\section{Keep it safe and simple}

Dental implant placement is complex. So, why not invest in technology that supports the procedure, making it simpler and safer while adding flexibility to the way you work?

Implantmed from W\&H is an innovative solution that has helped revolutionise implant placement for over 20 years.

Simple to use with an intuitive interface and colour touch screen, Implantmed provides secure torque control, has an automatic thread-cutter function and offers measurable implant stability. Plus, with upgrades such as wireless foot control you can ensure that you are free to work the way you want to, all the while enjoying the benefits of a truly cutting-edge system by your side.

To find out more visit www.wh.com/ en_uk, call 01727874990 or email office. uk@wh.com.

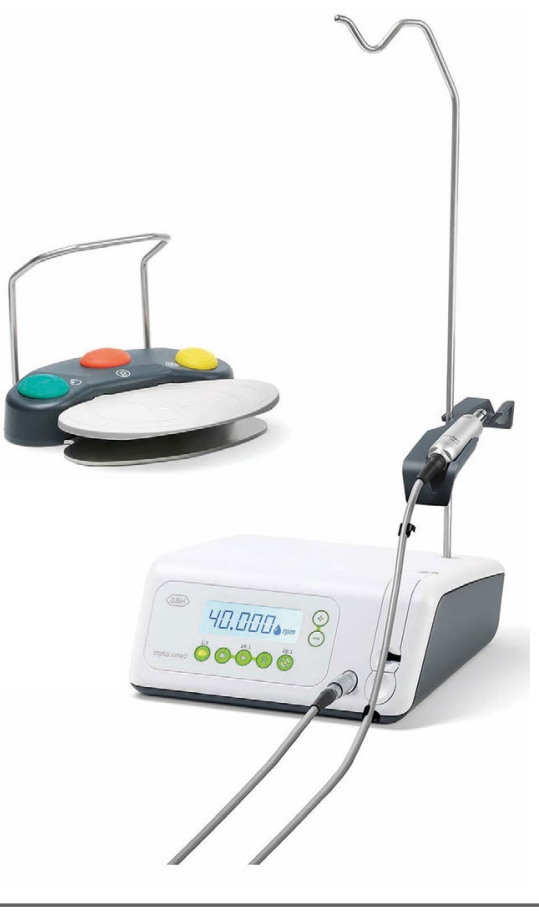

\title{
Exceptional care
}

When you invest in equipment, you want peace of mind that you can rely on exceptional support from the manufacturer

That's why when you purchase a system from Eschmann, we go above and beyond to ensure that we always offer our customers an exceptional standard of customer care.

As part of our Care \&

Cover policy, we provide scheduled annual validation and maintenance service visits in accordance with HTM 01-05 and SDCEP guidance, for total compliance. We also install the latest software updates for your systems free of charge, helping your practice to remain at the cutting-edge.

We have our own network of engineers, always guarantee fast response times and only use original parts during maintenance and repair so that your systems can continue to provide an unparalleled standard of infection control.

To find out more about Eschmann's service offerings visit www.eschmann.co.uk or call 01903875787.

\section{The WO0DI interdental brush}

If you want to respect the environment while protecting your patients' oral health, the WOODI is the perfect choice.

WOODI has a handle made from FSCcertified birchwood and, like all TANDEX

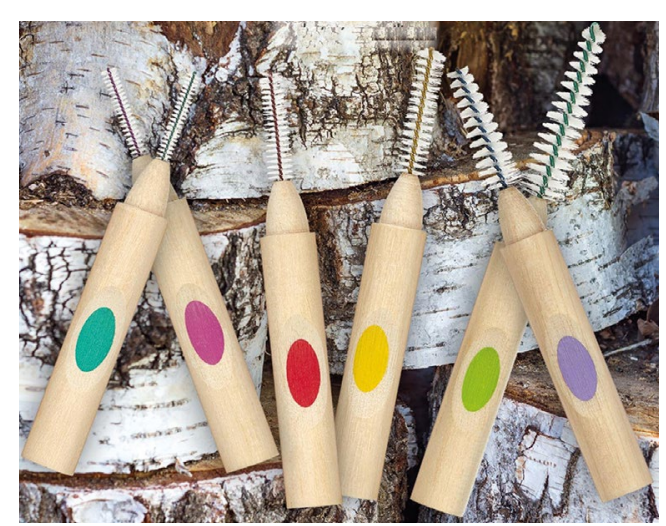

products, sustainable energy sources are used in its manufacturing.

For interdental cleaning, the WOODI is easy to use, available in six sizes for different spaces. Being able to gently loosen debris from between the teeth and around the gingiva will elevate your patients' oral hygiene between appointments, reducing their risk of disease.

The WOODI is coming soon keep your eyes on our website and social media.

For more information on Tandex's range of products, visit https:// tandex.dk/ or visit the Facebook page www.facebook.com/pages/Tandex$\mathrm{UK} / 234855250044190$ ? $\mathrm{fref}=\mathrm{ts}$

\section{Accredited training taking you from novice to implant referrals}

Accept referrals and bring in a new revenue stream when you have trained in how to place and restore dental implants.

The One to One Implant Education offers a fully accredited Postgraduate Diploma in Implant Dentistry.
Under the guidance and mentorship of Dr Fazeela Khan-Osborne you will receive quality learning combining theory, hands-on teaching and live surgery. In London's Harley Street, experienced instructors will start you on your implant journey so you can help more patients and return them to health.

Speak with The One to One Implant Education for a rewarding, profitable future.

To reserve your place or to find out more, visit https://121implanteducation.co.uk or call 02074860000 . 